\title{
PEDAGOGIA DA AUTORIA
}

\author{
Carmen Moreira de Castro Neves*
}

Abstract

Digital technology, insofar as it promotes interactivity, integration and media convergence, brought to the contemporary agenda the discussion on a new distance education. This new distance education rejects bureaucratized and inflexible projects that depersonalize course attendants and inhibit innovation and creativity. The proposal put forward in the text is a pedagogy that promotes authoring, based on strategies that view the student as the protagonist of the educational act, respecting the complexity of human beings and their totality and capacity to build significations and generate socially relevant knowledge. This article presents projects that are being developed by the Education and Culture Ministry Distance Education Secretariat, using authoring pedagogy. These projects seek to foster and translate numerous responses from individual and collective actors motivated to explore, analyze, contextualize, deepen, and expand their own view and experience with a given issue.

Keywords: Distance Education; Pedagogy; Authoring Pedagogy; Information Technologies; Communication; Interaction.

Especialistas em educação são unânimes em reconhecer que as novas tecnologias da informação e da comunicação revolucionaram a educação a distância, possibilitando interações que abrem caminho para processos educacionais com elevado padrão de qualidade e que se refletem na educação presencial, dando-lhe uma nova dinâmica. Podemos considerar que evoluímos quando não adjetivarmos mais a educação com presença ou distância e soubermos integrar harmoniosamente espaços e tempos de aprendizagem, trabalho individual e colaborativo, a produção de textos,sons e imagens. Trata-se de aprender de forma intencional, profunda e ética, valorizando os sujeitos - educadores e alunos. Para vencer esse desafio sempre adiado de valorização dos sujeitos, posto há muito por grandes educadores, o texto propõe a pedagogia da autoria, partindo do programa TV Escola e do curso Mídias na Educação, mas indicando sua relevância em todos os processos educacionais, inclusive na formação profissional.

\section{EDUCAR EM UM MUNDO SEM DISTÂNCIAS}

O final do século XX mudou definitivamente a educação a distância. As tecnologias da informação e da comunicação - TICs - trouxeram contribuições essenciais ao processo de educar e educar-se a distância, especialmente ao possibilitar interações síncronas e assíncronas de alunos e tutores (professores ou orientadores, dependendo do projeto) e de alunos entre si, prática que favorece o trabalho colaborativo.

Em decorrência dessas interações, todo o processo educacional passou a exigir revisão de paradigmas: planejamento, gestão, profissionais multidisciplinares, materiais didáticos, infra- estrutura, avaliações, relação tutor/ alunos, arquitetura da escola, investimentos. Todos os componentes da educação vêm sendo aperfeiçoados na perspectiva de colocar o aprendiz no centro do projeto educacional.

$\mathrm{Na}$ educação a distância contemporânea, a busca pela qualidade repele a massificação que caracterizou os cursos por correspondência de décadas passadas e investe em um atendimento mais personalizado, capaz de valorizar as múltiplas inteligências do ser humano.

Mas não foi só a educação a distância que mudou. A inserção das TICs na escolas - assim como em hospitais, empresas, bancos, supermercados, fábricas e em todas as atividades humanas - revigora a forma como se faz educação presencial. De fato, técnicas e metodologias de educação a distância passam a ser incorporadas ao diaa-dia da escola, anunciando uma outra evolução: a integração entre presença e distância. Assim, derrubam-se as fronteiras físicas da escola, abrem-se caminhos para novas fontes de pesquisa e conhecimento, ampliam-se os espaços educacionais, combinam-se momentos presenciais com virtuais, renova- se o papel de professores e gestores comprometidos com a concretização de uma educação contextualizada e de qualidade.

Nesse cenário e com o aumento do uso das redes, de equipamentos como as web-cams e de possibilidades de encontros síncronos, nota-se um esgotamento da expressão "educação a distância".

Em alguns países, a denominação educação a distância está sendo abolida, para representar um projeto educacional mediado por tecnologias em que as interações ora são presenciais, ora a distância: na Suécia, é educação flexivel, na 
Inglaterra, educação combinada; na China, educaşão móvel.

A verdadeira evolução será quando não for preciso adjetivar a educação com presencial ou a distância: simplesmente educação.

Infelizmente, o Brasil não está pronto para essa evolução: ainda discutimos legislação específica para EAD; ainda há perguntas sobre quanto deve ser o percentual para um curso ser considerado a distância ou presencial; ainda há dúvidas, mesmo em universidades, sobre haver ou não qualidade em um curso a distância; ainda são escassos e espasmódicos os investimentos em infra-estrutura tecnológica nas instituições públicas; as licenciaturas continuam diplomando professores sem domínio de diferentes linguagens e tecnologias; ainda não conseguimos sensibilizar as agências reguladoras e as empresas de telecomunicações para a importância de tarifas diferenciadas, o mais possível próximo de zero, para a área de educação; ainda falta aos estudantes a cultura de estudar de modo autônomo, independente e responsável; ainda não temos um laboratório em cada escola pública quanto mais computadores em cada sala de aula...

Nada disso, no entanto, deve ser motivo para desânimo. O panorama no país mostra experiências animadoras em educação básica, técnica, tecnológica, graduação, pós-graduação e corporativa, em instituições públicas e privadas.

A comparação entre o que há para ser feito e os bons resultados já alcançados deve motivar o país a definir políticas públicas para vencer desafios. E os principais desafios são: (1) a universalização da educação básica e a expansão da educação superior; (2) a valorização dos profissionais da educação, assegurando-lhes salário, formação continuada e condições de trabalho; (3) a adoção de modelos pedagógicos que efetivamente coloquem o aluno como foco da aprendizagem, garantindo elevado padrão de qualidade em todos os níveis, modalidades e etapas e (4) a democratização do acesso às tecnologias nas escolas, na perspectiva da inclusão digital da população ${ }^{1}$.

Os dois primeiros desafios são óbvios. Qualquer análise que seja feita sobre um país condiciona seu desenvolvimento humano e crescimento econômico ao nível de educação do seu povo. Universalizar a educação básica (apenas a fundamental já não é suficiente, principalmente em países de grande população de excluídos), expandir os índices de acesso à educação superior e ter profissionais bem formados e motivados são pilares para a soberania em um mundo globalizado.

Os dois últimos se interligam: qualidade na educação significa a formação de cidadãos éticos, capazes de construir conhecimento, ler e interpretar criticamente o mundo e de agir sobre a realidade, melhorando a própria vida e a da comunidade. Uma das estratégias para a qualidade no processo de ensino e aprendizagem é a adoção de uma pedagogia que coloque o aluno como centro da ação educacional. As tecnologias facilitam esse processo, modificando o papel do educador e dos alunos na sala de aula.

A Secretaria de Educação a Distância - Seed, do MEC, criada em 1996, conhece as resistências e incertezas quanto ao uso e impacto das tecnologias nos processos formativos, bem como os desafios da qualidade na educação presencial e a distância. Acreditando no potencial educativo das tecnologias e com base nas experiências de implantação dos programas2 TV Escola, curso TV na Escola e os Desafios de Hoje, Programa Nacional de Informática na Educação - Proinfo, Programa de Formação de Professores em Exercício Proformação, Paped e Rádio Escola, o Departamento de Produção e Capacitação em EAD da Seed, definiu como política para suas ações de capacitação, a partir de 2005, a pedagogia da autoria.

\section{A PEDAGOGIA DA AUTORIA}

A pedagogia da autoria busca concretizar desafios lançados por Paulo Freire, Vigotsky, Piaget, Morin e outros educadores que põem em relevo a complexidade e totalidade do ser humano e sua capacidade de construir significados e de gerar projetos e conhecimentos socialmente relevantes.

Como chegamos a ela? Em 2004, a TV Escola fez um convite aos alunos e professores, pelo próprio canal: mandem um vídeo com poesia e ele será veiculado na I Semana de Poesia da TV Escola, em outubro. Não havia prêmios ou ajuda financeira. Sugeriase às escolas um trabalho além dos muitos que ela já faz normalmente, apenas com a promessa de exibição do vídeo. Dos lugares mais distantes do Brasil, mais de 300 vídeos foram enviados e cerca de $50 \%$ com poesias de autoria dos próprios alunos. A reação dos alunos e a expectativa quanto a novas participações mostraram que, efetivamente, crianças e jovens estão prontos para criar e mostrar suas criações. Por isso, o Brasil é campeão em uso de Orkut, blogs e fotologs.

Além desse projeto, observaramse os resultados das quatro edições do curso a distância TV na Escola e os Desafios de Hoje (ofertado de 2000 a 2003), em que os educadores-cursistas precisavam desenvolver um projeto de trabalho final, aplicando o que haviam aprendido ao longo de 180 horas. A metodologia instrumentalizava os cursistas para o uso crítico e criativo de TV e vídeo em sala de aula, mas também os habilitava a produzirem seus próprios vídeos. 
A quantidade de professores que optou pela produção de um vídeo, em vez de um paper, como projeto de trabalho final surpreendeu à Seed e às universidades públicas envolvidas na tutoria e implementação do curso. E esses professores relataram que nunca mais assistiram à televisão como faziam antes e nunca mais trabalharam em classe como costumavam: sentiam-se muito mais críticos, confortáveis e seguros com o uso da TV e vídeo.

De fato, a maioria dos cursos sobre uso de tecnologias limita-se a formar um usuário. Ao deparar-se com os alunos, no entanto, o professor percebe-se diante de alguém que se aventura e cria páginas na web, blogs, fotologs, inventa filminhoscom a câmera digital, domina os recursos de um celular, enfim, alguém capaz de produzir.

Processos educacionais, portanto - sejam presenciais, sejam a distância -, devem ser mediados por tecnologias, mas não se restringir ao manuseio do equipamento e à mera reprodução do que já está feito.

A pedagogia da autoria é intencional, profunda, ética. Parte do conhecimento que está produzido fica disponível em livros, revistas, jornais, televisão, vídeos, internet, CD-ROMs, DVDs, dicionários, etc. Mas não pára aí: a partir da exploração, análise e da experimentação diretas de todos esses recursos, os professores e alunos expressam- se por meios de suas próprias produções, também utilizando esses mesmos recursos: textos, internet, vídeos, programas de rádio etc., inclusive combinando-os entre si. O compartilhamento do processo de produção e a avaliação dos produtos geram novas análises, visões interdisciplinares e novas produções, impulsionando um contínuo crescimento.

Trata-se, pois, de uma pedagogia que incentiva o uso integrado de múltiplas linguagens e promove a autoria e o respeito à pluralidade e à construção coletiva, reconhecendo nos alunos, professores e gestores sujeitos ativos e não passivos.

Esta idéia, como já foi dito, não é nova, mas vem sendo sempre um desafio raramente vencido. Como, portanto, concretizar a pedagogia da autoria?

O Departamento de Produção e Capacitação em Educação a Distância da Seed estabeleceu duas estratégias básicas. A primeira partirá de uma nova forma de oferecer os programas da TV Escola; a segunda adota a própria pedagogia da autoria para os cursos de formação continuada nas mídias que enriquecem a educação. Há uma terceira estratégia, relacionada à infra-estrutura tecnológica, que, apesar de não estar afeta ao Departamento, é necessária à consolidação dessa proposta. A seguir, apresentam- se algumas idéias sobre as referidas estratégias.

\section{A PEDAGOGIA DA AUTORIA NA TV ESCOLA}

A TV Escola passa a adotar, em 2005, uma pedagogia nova na produção de seus próprios programas. O objetivo é levar às escolas públicas estratégias didáticas capazes de estimular educadores e alunos a serem leitores críticos, autores criativos e cidadãos conscientes do potencial e dos limites da mídia, livres da manipulação e da massificação que pode ser exercida pelos meios de comunicação.

A proposta é a produção de programas para a TV Escola no seguinte formato: pré-exibição; exibição e pósexibição.

1. Pré-exibição: concisa orientação e preparação do educador para a análise do vídeo e sua futura utilização, dentro e fora da sala de aula. A préexibição vai ao ar pela TV Escola, podendo estar também na internet e em impressos, e busca atrair o educador, despertando seu interesse em relação aos objetivos, conhecimentos e competências que podem ser explorados com o programa, assim como seu uso multidisciplinar, além de auxiliálo a preparar um plano de aula mais completo e diferenciado;

2. Exibição: é o programa televisivo que vai ao ar pela TV Escola e que aborda determinado tema, utilizando todos os recursos da moderna televisão, garantidas qualidade de áudio, imagem e conteúdo científico-culturaleducacional. A exibição terá uma duração máxima de 55 minutos, mas deverá ser desenvolvida em episódios, segmentos ou capítulos menores, de modo a permitir à TV Escola e às escolas um uso mais flexível, adaptando-se ao tempo de aula e às diferentes situações pedagógicas, inclusive facilitando a indexação e o download via internet;

3. Pós-exibição: é o conjunto de atividades multimeios que complementa a aprendizagem proporcionada pelo vídeo e que será disponibilizado no e-proinfo ${ }^{3}$ - ambiente de aprendizagem da Seed/MEC. Aqui o aluno poderá testar e aprofundar os conhecimentos adquiridos por meio de textos complementares, sites e vídeos correlacionados, jogos educativos, Webquest, enquetes, acervo de imagens, mural de publicações, games etc. Essas ferramentas serão desenvolvidas em diferentes tecnologias, para democratizar o acesso e permitir seu uso antes mesmo de estar disponível a tecnologia de televisão digital interativa, podendo migrar para ela, assim que possível. É função da pós-exibição incentivar a autoria. Espera-se que alunos e professores - a partir do roteiro do programa, do vídeo digitalizado e indexado e das inúmeras sugestões de atividades - desenvolvam suas 
próprias idéias, programas e projetos, harmonizando o global com o local e contextualizando a educação, sentindo-se responsáveis e ativos na construção da própria história e a da sua comunidade.

Como primeiro passo no desenvolvimento dessa proposta, houve o lançamento da I Chamada Pública para seleção de conteúdos educacionais, no âmbito do Programa de Fomento à Produção de Programas Educacionais Multimeios, sobre temas relativos à Língua Portuguesa e Matemática, a partir das matrizes curriculares da $4^{a}$ série do ensino fundamental estabelecidas pelo Sistema Nacional de Avaliação da Educação Básica - Saeb ${ }^{4}$.

Constitui objeto da I Chamada Pública a premiação de programas educacionais que abordem um determinado conteúdo de Língua Portuguesa e Matemática, desenvolvidos a partir do formato de préexibição, exibição e pósexibição.

Ao definir o Saeb como ponto de partida do Programa de Fomento à Produção de Programas Educacionais Multimeios, a TV Escola ratifica seu compromisso com a qualidade na educação e estabelece como espinha dorsal da produção própria dois domínios essenciais a todo cidadão: o da língua materna e o do raciocínio lógicomatemático. Na continuidade do Programa de Fomento, deseja-se atingir a 8 a série e o ensino médio (neste nível, unindo-se os referenciais do Saeb e Enem). Essa opção não quer dizer que outras áreas curriculares estarão fora da programação da TV Escola. Trata-se de uma prioridade da produção própria, visto que programas dasdemais disciplinas (Artes, Geografia, História e outras) podem ser encontrados com mais facilidade no mercado nacional e internacional. $\mathrm{Na}$ medida da disponibilidade de recursos financeiros, a área de Ciências também deverá ser contemplada nas próximas Chamadas Públicas, tendo em vista a necessidade de desenvolver a curiosidade e o espírito científico dos nossos estudantes.

\section{A PEDAGOGIA DA AUTORIA NA FORMAÇÃO CONTINUADA DE EDUCADORES}

Uma inovação provoca impacto na educação e é incorporada nas escolas somente se gestores e professores acreditarem nela, perceberem seu potencial pedagógico e souberem explorá- la adequadamente.

Assim, a formação continuada para o uso das diferentes linguagens e tecnologias na educação, proposta pelo Departamento da Seed responsável pela capacitação, leva em conta a avaliação de todos os cursos realizados como suporte à TV Escola, Proinfo, Proformação e Rádio Escola.

O projeto que está em processo de desenvolvimento, iniciado em outubro de 2005, é o "Programa de Formação Continuada Mídias na Educação".

Nele, há duas premissas básicas: a pedagogia da autoria e a integração das mídias. Ou seja, a proposta ousada é que, ao final da trajetória do programa, o educador saiba produzir e utilizar as quatro linguagens e tecnologias básicas, que deveriam estar presentes em todas as escolas: material impresso, televisão, informática e rádio.

O programa está estruturado em módulos temáticos. O acesso se dá por meio do módulo introdutório, conceitual: "Integração de Mídias na Educação: concepções e tendências", para que os educadores tenham clareza quanto ao potencial e à irreversibilidade do uso de mídias na educação.Complementa-o o módulo "Gestão de Mídias", para que sejam enfrentados os desafios institucionais de inserção das tecnologias nas salas de aula, escolas e nos sistemas de ensino. Os temas representativos das mídias e suas principais aplicações educacionais constituem blocos temáticos e são: Televisão, Rádio, Informática e Material Impresso. Cada uma das mídias será desdobrada em diversos módulos, garantindo o domínio por parte dos educadores. Haverá níveis crescentes de aprofundamento em cada um desses temas e será garantida a integração entre eles, como, por exemplo, na oferta de "Rádio na Web" ou "Hipertexto no Material Impresso".

A estrutura modular permitirá que novos módulos sejam incorporados ao programa, sempre que se constate demanda ou novas perspectivas tecnológicas, mediante análise da relevância do tema em questão. Múltiplos percursos podem ser desenhados, desde que seja respeitada a característica integradora das mídias entre si e ao projeto pedagógico.

Para incentivar os cursos de licenciatura e de pós-graduação a inserirem as mídias no processo de formação de educadores, buscou-se estabelecer uma correspondência entre a estrutura modular proposta e a oferta usualmente verificada nas disciplinas das universidades, no que diz respeito à sua duração. Nesse sentido, cada módulo deve ter duração mínima de 15 horas, correspondendo a um crédito. Universidades públicas serão parceiras na implementação do curso, mas, futuramente, a proposta será aberta a todos os que tenham interesse em uma formação no tema.

Os módulos do programa estão estruturados em três Ciclos, permitindo o tratamento dos assuntos em diferentes níveis de profundidade, a saber: extensão (120h), aperfeiçoamento (180h) e especialização (360h). Dessa forma, os educadores poderão trilhar um verdadeiro processo de educação continuada. Outras formas de certificação serão possíveis: em módulos e em temas avulsos, resguardadas uma unidade didática e a produção de um trabalho final. 
Para todos os níveis, o Projeto “Galeria das Mídias” constituirá um espaço virtual de visualização das produções realizadas durante o programa. Será o espaço das múltiplas autorias.

\section{A PEDAGOGIA DA AUTORIA E A INFRAESTRUTURA}

A pedagogia de incentivo à autoria está ancorada em uma infra-estrutura que fomenta e traduz as inúmeras respostas de atores individuais e coletivos motivados a explorar, analisar, contextualizar, aprofundar, expandir, enfim, a produzir sua própria visão e experiência sobre determinado tema.

Por que iniciar pela TV Escola, integrando-a ao Proinfo? Em primeiro lugar, pela base instalada nas escolas públicas, que, segundo o Censo do Inep em 2004, é a indicada no Quadro 1.

Em segundo lugar, porque há na Seed a política de integração de programas, projetos, mídias e linguagens.

Em terceiro lugar, porque a discussão sobre a TV digital interativa no Brasil ainda não está definida. A Secretaria considera que, com a pedagogia da autoria, pode contribuir para agregar novos e importantes elementos à pesquisa e debates sobre o tema.

A maioria das pautas que discute as possibilidades da tecnologia digital e da integração e convergência de mídias está concentrada em dois pontos básicos: os que se referem à infra-estrutura e os que dizem respeito à produção e veiculação de conteúdos, levando em conta o potencial de interatividade.

A discussão sobre interatividade na TV digital, todavia, está pautada principalmente por aquilo que interessa aos canais comerciais: maior audiência, mais patrocinadores, novos mercados, maior lucro.

Tal opção orienta a definição da infra-estrutura tecnológica necessária à promoção dessa interatividade que permitirá, por exemplo, a escolha de filmes e horários, a seleção de diferentes finais (entre os preparados pelas emissoras), a possibilidade de definir horários alternativos, o acesso aos sites dos patrocinadores e outros serviços.

Nada contra essa vertente, mas ela se fundamenta na capacidade de manipulação e massificação da mídia, mesmo levando em consideração os serviços customizados.

É na educação, todavia, que a TV digital interativa alcança seu mais nobre ideal de interatividade: o que cha-ma o telespectador para a análise crítica dos conteúdos, nele despertando o desejo de agir, de produzir e de divulgar 
suas criações. É uma interatividade que, como diz Marco Silva ${ }^{5}$, reconfigura as relações e as comunicações humanas em toda a sua amplitude.

Para que isso aconteça, é preciso equipamento e hardware compatíveis. Do ponto de vista tecnológico, o middleware do terminal de acesso deverá ser concebido, especificado e desenvolvido de forma a facilitar os serviços e sua atualização, seja na alteração de interface com o usuário seja na incorporação de novas funcionalidades. O serviço deve apresentar uma interface de usuário com características como:

.. ter interface gráfica com elementos facilmente reconhecíveis;

.. permitir a disponibilização de conteúdos e aplicações pedagógicas;

.. ser auto-explicativa;

.. ser de fácil utilização/navegação mesmo para usuários com pouca familiaridade no universo digital;

.. ser de fácil memorização;

.. possuir aspecto agradável;

.. ser aderente a padrões de usabilidade e ergonomia.

Do ponto de vista pedagógico, a interatividade deve possibilitar, por meio de um canal de retorno, a comunicação assíncrona/síncrona do usuário com aplicativos residentes no ambiente do provedor do serviço, mediando, inclusive, comunicação com outros usuários. As informações geradas pelo usuário podem ser temporariamente armazenadas e, posteriormente, enviadas ao provedor do serviço pela prestadora de serviços de telecomunicações, conforme a solução de canal de retorno a ser adotada. Como a TV Escola não tem a proposta desubstituir o professor, a comunicação exigida pelo serviço não necessita ocorrer em tempo real (máximo de instantaneidade), pois ela se baseia em informações que podem ser processadas posteriormente, sem prejuízo do desempenho da aplicação.

Há duas grandes questões a resolver. A primeira é desenvolver uma tecnologia e uma produção de conteúdos educacionais que seduzam o usuário, fazendo-o abandonar a atitude quase sempre passiva que adota ante a TV comercial e impulsionando- o a interagir e a produzir. A segunda é desenvolver uma tecnologia cujo canal de retorno suporte as múltiplas produções de alunos e professores.

Enquanto não se define a questão da TV digital interativa no Brasil, é fundamental o uso da TV Escola combinado ao Programa Nacional de Informática na Educação - Proinfo e a outras iniciativas de levar computadores às escolas. Por meio de um computador conectado, é possível terse um retorno mais ágil da produção das escolas. Outros recursos, no entanto, como correio, fax, vídeos e CD ROMs também serão considerados, no sentido de dar visibilidade à autoria dos alunos e professores e de democratizar a pedagogia da autoria. A televisão por IP é um outro caminho que vem sendo explorado e que pode dar novos rumos ao uso da TV e vídeo na escola.

A qualidade na educação é um conjunto de fatores, entre os quais estão as condições de trabalho e de acesso às tecnologias. Os números anteriormente apresentados mostram que ainda há muito a ser feito nesse campo. O Poder Público no Brasil precisa, de forma solidária e cooperativa, investir decisiva e continuamente dotando todas as instituições educacionais públicas de tecnologias da informação e da comunicação. Trata-se de um imperativo categórico: atualmente não é possível ser um bom profissional e realizar um trabalho com elevado padrão de qualidade, em área alguma, sem acesso e domínio das tecnologias.

\section{APLICAÇÕES DA PEDAGOGIA DA AUTORIA}

A pedagogia da autoria interessa ao Senac, Senai, Sesi, Senar e Sebrae, a universidades e a outras instituições ou empresas que investem em educação a distância?

A resposta é: sem dúvida alguma.

Um dos riscos da educação a distância é a centralização e a tendência a uma padronização e homogeneização das respostas dos cursistas, facilitando a gestão didática e administrativa do curso, Em outras palavras, valoriza-se mais a instrução do que a educação; mais a reprodução do que a criatividade; mais a repetição do que uma construção que possa abrir caminhos não previamente pensados.

Todo processo que não se limita a adestramento e deseja ser efetivamente educacional busca formar um cidadão 
competente, criativo, capaz de aprender autonomamente. Se a pedagogia que embasa um curso levar à autoria, se os tutores e gestores do curso forem preparados para orientar nesse sentido, se os materiais e as tecnologias disponíveis reforçarem a análise crítica, a iniciativa e o desejo de criar, então teremos pessoas que vêem sua autoestima reforçada e que se motivam a buscar novos patamares, investindo em educação ao longo de toda a vida.

As instituições que estão envolvidas com formação profissional sabem que o mercado de trabalho contemporâneo está cada vez mais exigente e procura profissionais tecnicamente competentes, mas também capazes de integrar vários campos do conhecimento, com habilidade para juntar teoria e prática, com iniciativa para enfrentar e resolver problemas, com domínio de informática e de idiomas, com capacidade de trabalhar em equipe, um profissional que esteja aberto à atualização permanente e que seja capaz de criatividade, liderança, responsabilidade social...

A proposta da pedagogia da autoria não é uma construção vazia nem de transferência de responsabilidades (do professor para os alunos). É um processo marcado pela riqueza de estratégias didáticas, intencionalidade e profundidade, que se inicia com a exploração (busca de informações em diferentes fontes: livros, TV, internet etc.), continua com a experimentação (comparar, argumentar, testar, extrapolar, enfim, descobrir o que fazer com as informações) e conclui com a expressão direta (autoria, a partir das informações coletadas, analisadas e trabalhadas). Na pedagogia da autoria devem ser consideradas as múltiplas inteligências dos indivíduos, as inúmeras possibilidades de abordagem multidisciplinar e os desafios tecnológicos e de linguagem que decorrem de uma proposta de criação - o que implica destacar, também, a importância da construção colaborativa. Ao assumir o compromisso de expor sua produção à sociedade, o autor torna-se mais consciente e atento à construção do conhecimento e às implicações éticas de seu trabalho.

Assim, descartam-se propostas de cursos em que os professores não planejam previamente e o aluno vai fazendo o que quiser, sem uma organicidade que lhe permita ao final ter construído um sólido conhecimentosobre o tema a que se propôs estudar e produzir.

Não se trata de uma utopia: nossas vivências na Seed mostram essa realidade. Todos os professores que terminam o Proformação transformam- se em leitores competentes, executam projetos finais relevantes para a comunidade em que estão inseridos e passam a demandar por cursos superiores; muitos educadores utilizaram seu trabalho final no curso TV na Escola e os Desafios de Hoje como projeto para ingresso em mestrados ou especializações; muitos tutores renovaram sua prática no ensino presencial e investiram na elaboração de dissertações e teses sobre o assunto; algumas universidades, como a Ufal e a UnB, incorporaram o curso TV na Escola e os Desafios de Hoje em suas graduações e, fundamentalmente, todos os que passam a dominar as tecnologias percebem que podem trabalhar melhor e crescem como pessoas e como profissionais, razão pela qual ninguém que aprende a explorar as tecnologias abandona seu uso e retorna às velhas aulas restritas a giz e cópias. Assim concebida, a educação acaba com a dicotomia entre o virtual e o presencial; transforma as inúmeras fontes de informação em motivos para a construção do conhecimento; valoriza todos os sujeitos envolvidos no ato educacional; integra estratégias didáticas, linguagens e tecnologias; harmoniza o global com o local; promove valores éticos de respeito à pluralidade e de compromisso solidário. Uma educação assim concebida adquire qualidade e deixa de ser distante da vida das pessoas, das realidades do mercado de trabalho, das exigências de um mundo tecnologicamente desenvolvido e globalizado, ajudando a vencer os desafios de consolidação de um país desenvolvido economicamente e justo socialmente.

A pedagogia da autoria é uma proposta que contribui para formar sujeitos conscientes, partícipes e autônomos: é uma proposta de qualidade para a educação.

\section{NOTAS}

1 Segundo o Censo Escolar do Inep, no Brasil, há cerca de 6,5 milhões de crianças em creches e pré-escolas, 36 milhões de alunos na educação fundamental, perto de 12 milhões de jovens no ensino médio, quase 4 milhões no ensino superior e aproximadamente 2,7 milhões de funções docentes em exercício nesses níveis de ensino. Esses educandos e educadores estão distribuídos em mais de 300 mil estabelecimentos de ensino, representando uma capilaridade que nenhuma outra instituição brasileira - hospitais, bancos ou agências de correios - atinge. Se além desses cidadãos matriculados, as escolas alcançarem, pelo menos, um pai ou uma mãe em ações educativas, será possível a construção de um país com justiça social.

2 Conheça mais sobre esses programas no endereço eletrônico: http://portal.mec. gov.br/seed.

3 Ver em http://portal.mec.gov.br/seed.

4 Os dados do Saeb-2003 indicam uma situação dramática na educação brasileira: em Leitura, estão no 
estágio de proficiência considerado "adequado" apenas 4,8\% dos estudantes de $4^{\mathrm{a}}$ série; $10,3 \%$ de $8^{\mathrm{a}}$ série e $6,2 \%$ da $3^{\mathrm{a}}$ série do ensino médio. Em Matemática, estão no estágio "adequado" somente $6,4 \%$ dos nossos alunos de $4^{\mathrm{a}}$ série; $2,7 \%$ de $8^{\mathrm{a}}$ série e $6,9 \%$ do ensino médio. Além disso, a taxa de conclusão do ensino fundamental é de 57,1\%, apesar de a média de estudos ser de 8,6 anos. Como conseqüência, o Superior Tribunal Eleitoral indica que, de 120 milhões de eleitores, cerca de 70 milhões são analfabetos ou analfabetos funcionais.

5 SILVA, Marco. Sala de Aula Interativa. 3. ed. Rio de Janeiro: Quartet, 2002.

* Mestre em Política, Planejamento e Gestão da Educação, pela UnB/DF. Especialista em Políticas Públicas e Gestão Governamental, atualmente exercendo a função de Diretora do Departamento de Produção e Capacitação em Educação a Distância, na Secretaria de Educação a Distância do MEC.

E-mail: carmen.neves@terra.com.br

\section{RESUMEN}

\section{Carmen Moreira de Castro Neves. Pedagogía de la Autoría.}

Al promover la interactividad, la integración y la convergencia de los medios, la tecnología digital incluyó la discusión acerca de una nueva educación a distancia en la agenda contemporánea. Esta nueva EAD rechaza proyectos burocráticos e inflexibles que despersonalizan a los estudiantes e inhiben la innovación y la creatividad. La propuesta del texto es la de una pedagogía que promueva la autoría a partir de estrategias que reconozcan al alumno como protagonista del acto educativo y que respeten la complejidad y la totalidad del ser humano y su capacidad de construir significados y generar conocimientos socialmente relevantes. Se presentan proyectos desarrollados por la Secretaría de Educación a Distancia del Ministerio de Educación que emplean la Pedagogía de la Autoría, los cuales intentan fomentar y traducir las innumerables respuestas de actores individuales y colectivos motivados a explorar, analizar, contextualizar, profundizar y expandir, o sea, producir sus propias visiones y experiencias acerca de determinado tema. Palabras-Clave: Educación a Distancia; Pedagogía; Pedagogía de la Autoría; Tecnologías de la Información; Comunicación; Interacción. 